ACTA ARACHNOL., XXV, (2), 1974.

\title{
On Some Oonopidae from Japan and Formosa (Araneae)
}

\author{
Paolo Marcello BRIGNOLI \\ Zoological Institute of the University, Roma, Italy
}

During a short visit in Hamburg I obtained in loan from the Zoologisches Museum a few undetermined Oonopidae from Formosa; as the study of this material requested the examination of the types of some Japanese Oonopidae, I resolved to publish a short note over all these species.

I express my most sincere thanks to Dr. Manfred Grasshoff (Senckenberg Museum, Frankfurt/Main), Dr. Manfred MoRITZ (Zoologisches Museum, Berlin), Dr. Gisela RACK (Zoologisches Museum, Hamburg), Dr. Izumi KAYAShima (Tokyo) and Dr. Takeo Yaginuma (Arachnological Society of East Asia, Osaka) who, through loan of types or other material or through bibliographical help, have made this study possible.

\section{Foreword}

Up to this time, for what I know, two Oonopidae were known from Formosa; of Japan (incl. the Ryu Kyu islands) about a dozen species were named. Three, i.e. Gamasomorpha cataphracta KARSCH, 1881, G. karschi BösENBERG \& STRAND, 1906 and Oonops corticalis BösENBERG \& STRAND, 1906 were described in the first papers over Japanese spiders and their types are in European museums (I examined them all). The first species described by a Japanese author was Gamasomorpha narutomii NAKATSUDI, 1942 published in one of the many Japanese papers of the period between 1930 and 1950 which, for one reason or another (mostly because they were not listed in the Zoological Record), were unfortunately ignored by arachnologists of other countries.

In more recent years quite a number of species has been described: Orchestina sanguinea OI, 1955, O. okitsui Or, 1958, Ischnothyreus japonicus Or, 1958, Gamasomorpha kusumii Komatsu, 1963, G. syarakui Komatsu, 1967, Tetrablemma shimojanai Komatsu, 1968. The last of these species, as I have already elsewhere demonstrated (BRIGNOLI, 1972) ' belongs to the family Tetrablemmidae, which is only superficially similar to the Oonopidae. Gamasomorpha narutomii belongs to the genus Ischnothyreus and is identical with $I$. japonicus (YAGINUMA, in litteris).

Three names, two of which at least appeared also in the Zoological Record, are following the informations of Dr. YaGINuma, nomina nuda: Orchestina nipponica KIsHida, Gamasomorpha okinawana KISHIDA and Citepectris strandi KISHIDA (the two last appeared in OKADA, 1959); also the genus Citepectris is a nomen nudum. 
In the material at my disposition I had no Orchestina and so I shall not discuss problems over this genus. As every student of the Oonopidae knows, the generical division of this family is extremely unsatisfying; for this reason I shall have to discuss briefly some problems of the genera here considered.

\section{Gamasomorpha cataphracta $\mathrm{K}_{\mathrm{ARSCH}}, 1881$}

Examined material:

Japan, leg. Doenitz, 1 (lectotypus), 1 우 (paralectotypus; both Zool. Mus. Berlin No. 3523).

Japan, Saga, 1882, Dönitz lez., 6 소, 18 우 우 ( +1 우 abdomen; all Senck. Mus. Frankfurt No. 2781 ; Bösenberg \& STRAND det.).

Same locality, 1 우 (Senck. Mus. Frankfurt No. 2782; Bösenderg \& STrand det. Gamasomorpha karschi; apparently syntype of this species).

Japan, Saga, 1882, Dönitz leg., 6 令 (Senck. Mus. Frankfurt No. 2865; syntypes of Oonops corticalis BöSENBERG \& STRAND, 1906 (NEW SYNONYMY).

Formosa, Akau, 23.4. 08, H. Sauter leg., 1 \$, 7 우우 (Zool. Mus. Hamburg).

Notes: in the Berlin Museum collection should be 5 other $\hat{\delta}$ (syntypes) which were not sent to me; in the SMF 2781 series was a 우 of Pseudotriaeris karschi (Bösenberg \& STRAND) 1906 -see later-; in the SMF 2782 tube (types of Gamasomorpha karschi), were one $\{$ (which really belonged to this species) and a $ᄋ$ of $G$. cataphracta.

Redescription- $-\hat{0}$ : prosoma reddish, lightly granulated, elongated, more elevated at $3 / 4$ of its length, posteriorly declining somewhat abruptly; 6 eyes in two straight rows; $\mathrm{AL} / \mathrm{PL}: \mathrm{PM}=5: 4$; posterior eyes neared, anterior eyes - very slightly separated. Labium triangular, as long as wide; sternum orange red, heart-shaped, its obtuse point separates the 4th coxae of their diameter; on its surface, after the labio-sternal suture, can be seen a small "step" on which the embolus is rested. Chelicerae, s. fig. 5. Pedipalp, s. fig. 3, with long embolus and conductor (fig. 4). Legs yellowish, without spines; coxae 1, 2, 4 elongated, 3 quadrangular. Opisthosoma with a dorsal and a ventral yellowish shield; there is also a small inframammillar shield; colulus very small (s. fig. 1).

우: similar to the $\hat{\delta}$, but sternum without "step"; vulva, s. fig. 2, very

\begin{tabular}{ccccccc}
\hline S-Legs & Femora & Patellae & Tibiae & Metatarsi & Tarsi & Total \\
\hline I & 0.43 & 0.25 & 0.33 & 0.31 & 0.17 & 1.49 \\
II & 0.41 & 0.22 & 0.33 & 0.27 & 0.15 & 1.38 \\
III & 0.35 & 0.18 & 0.27 & 0.26 & 0.13 & 1.19 \\
IV & 0.50 & 0.25 & 0.37 & 0.35 & 0.22 & 1.69 \\
\hline
\end{tabular}


difficult to examine, with a large posterior seminal receptacle which is situated very anteriorly and masks the -anterior- receptacle.

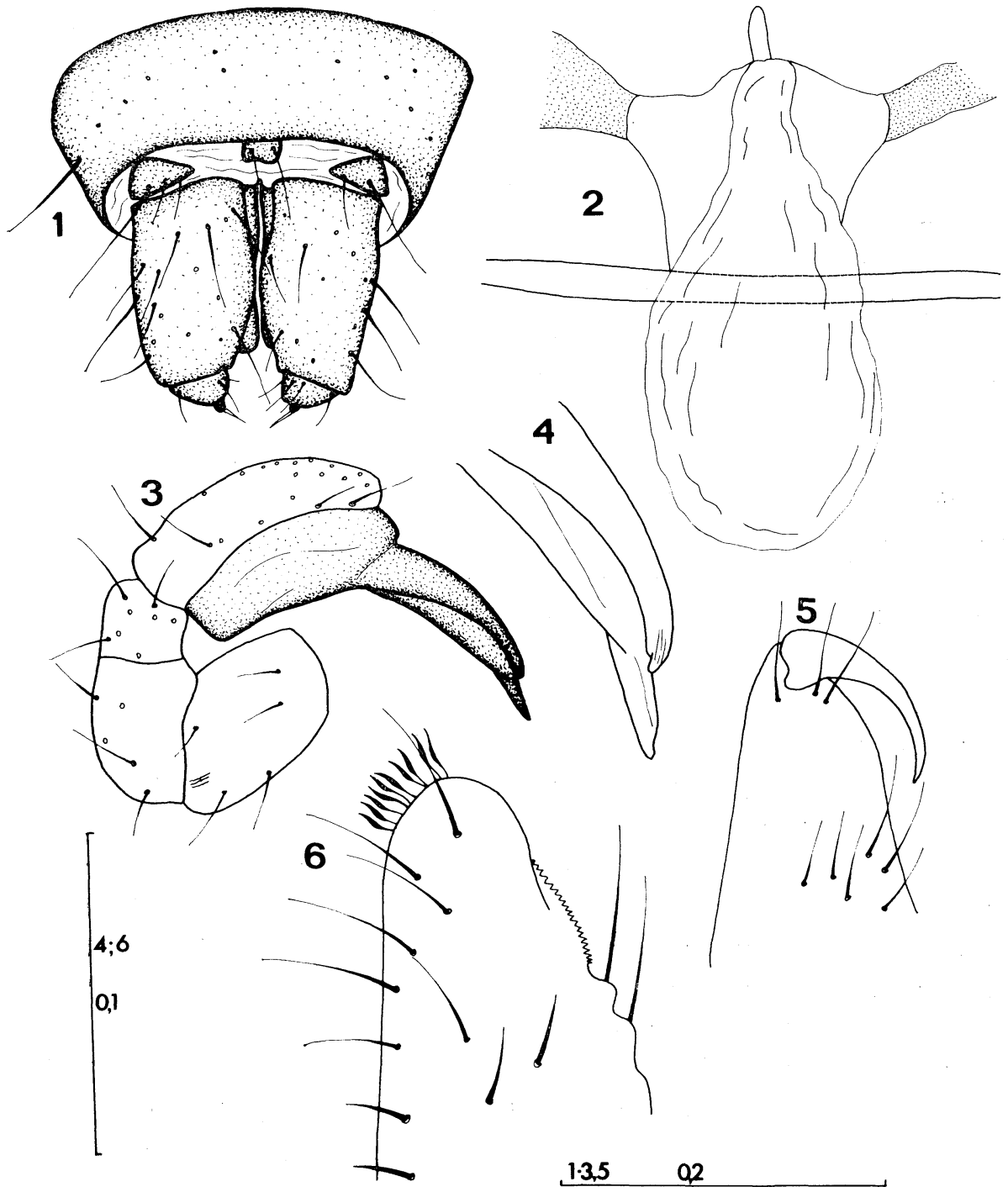

Gamasomorpha cataphracta KARscH, 1881

Fig. 1: spinnerets and colulus; fig. 2: vulva (from the inside; practically only the posterior seminal receptacle is visible); fig. 3 : pedipalp of the $\hat{o}$; fig. 4 : embolus and conductor: fig. 5: chelicera: fig. 6: gnathocoxa; scales in $\mathrm{mm}$. 
Dimensions (in $\mathrm{mm}$, slightly approximated; $\uparrow$ lectotype): prosoma 0.80 long, 0.62 wide; opisthosoma 1.00 long. Total length: 1.80 . $\$$ paralectotype : prosoma 0.81 long, 0.62 wide; opisthosoma 1.25 long. Total length: 2.06 .

\begin{tabular}{ccccccc}
\hline Legs & Femora & Patellae & Tibiae & Metatarsi & Tarsi & Total \\
\hline I & 0.46 & 0.25 & 0.36 & 0.32 & 0.18 & 1.57 \\
II & 0.43 & 0.18 & 0.33 & 0.32 & 0.18 & 1.44 \\
III & 0.42 & 0.18 & 0.30 & 0.30 & 0.17 & 1.37 \\
IV & 0.52 & 0.31 & 0.42 & 0.43 & 0.22 & 1.90 \\
\hline
\end{tabular}

Discussion: the syntypes of Oonops corticalis are without exception juvenile individuals which -now- are completely white; as always in the Gamasomorphinae their shields are not strongly sclerifield; their general morphology, colour and apparently not sclerified opisthosoma explain the fault by BöSENBERG \& STRAND.

Gamasomorpha cataphracta is the generotype of Gamasomorpha KARSCH, 1881, a genus to which have been attributed many species of most parts of the world by many authors who have unfortunately followed SIMON in his lack of understanding of the taxonomical importance of the genitalia in this family. Few characters of $G$. cataphracta can be considered specialized: this species is one of the many strongly sclerified Oonopidae, with simple chelicerae and no peculiarities in the eyes or in sternum and labium. The absence of spines on the legs is noteworthy as in approximately $50 \%$ of the genera of the Oonopidae there are spines; its value as character is naturally small. The o genitalia, which I have found very interesting in many genera, are not easily understood, at least in this species: the only sure fact is the presence of a large posterior seminal receptacle (as in many other genera). For the moment I would suggest to consider near to G. cataphracta (i. e. belonging to the same genus) only the species with similar $\hat{o}$ genitalia, with a small bulbus, a long laminar embolus intimately associated with a similarly long and laminar conductor, simple pedipalpi and, naturally, similar as general morphology.

Of the three other Japanese Gamasomorpha, G. karschi BöSENBERG \& STRAND can not be maintained in this genus (see later); G. syarakui KomATSU, by the $\hat{\delta}$ pedipalp belongs to Opopaea (see later); G. kusumii Komatsu (of which only the $f$ is known) is similar by general morphology, but has spines 
on tibiae and metatarsi of the first two pairs of legs and by this character remembers the Mediterranean species normally attributed to Dysderina. It is to be remembered that the generotype of this genus (D. principalis KEYSERLING) is South American and is possibly not congenerical with the Palearctic and Oriental "Dysderina."

True Gamasomorpha, strictly related to the generotype, are many Pacific species, as G. lalana SUMAN, 1965 or G. loricata (L. KocH, 1872); most records of this last species should be controlled as the morphology of the $\hat{\delta}$ bulbus is not at all so easily undertood and f.i. the illustrations of it given by BERLAND (1933) and ROEWER (1963) are quite different. Gamasomorpha cataphracta and Oonops corticalis had been recorded from Formosa by KAYASHIMA (1943).

\section{Pseudotriaeris n. gen.}

Diagnosis: a rather unspecialized genus of the Oonopidae (by general morphology), with reduced sclerifications, with extremely complicated $\hat{\delta}$ genitalia (a short embolus, a relatively short and partially membranaceous conductor and two other apophyses all emerging from a relatively large bulbus). Pedipalp with short and thick articles (tibia the largest).

Generotype: Gamasomorpha karschi BöSEnBerg \& STRAnd, 1906.

Notes: for the complete description and the discussion, see under the redescription of the generotype.

\section{Pseudotriaeris karschi (BÖSENBERG \& STRAND, 1906), n. comb.}

Examined material:

Japan, Saga, 1882, Dönitz leg., 1 令 (lectotype; Senck. Mus. Frankfurt No. 2782; type of Gamasomorpha karschi).

Some locality and date, 1 우 (Senck. Mus. Frankfurt 2781; labeled Gamasomorpha cataphracta).

Note: as this species is easily distinguished from $G$. cataphracta and Bösenberg \& STRAND had a couple of it, probably some time or another the 우 has been misplaced.

Redescription- $-\hat{0}$ : prosoma -now- pale yellow, elevated, rounded (almost as in Ischnothyreus); 6 oval eyes, the 4 posterior in a row with a slight posterior concavity, the 2 anterior situated between the PL and the PM of each side; all eyes very neared; $\mathrm{PM}: \mathrm{AL} / \mathrm{PL}=7: 5$. Clypeus vertical, much longer than the PM (at least $2 \times$ ). Gnathocoxae converging before the labium; labium 
triangular, longer than broad; labio-sternal suture evident; sternum heartshaped, whitish, smooth, truncated (its apex separates the 4th coxae approximately of their diameter). Chelicerae, s. fig. 8; pedipalp, s. fig. 7 . Legs yellowish, without spines or other modifications; coxae nearly globular; 2 tarsal claws on onychium, principal claws with a double series of teeth. Opisthosoma dorsally with a complete whitish shield; ventrally only the region

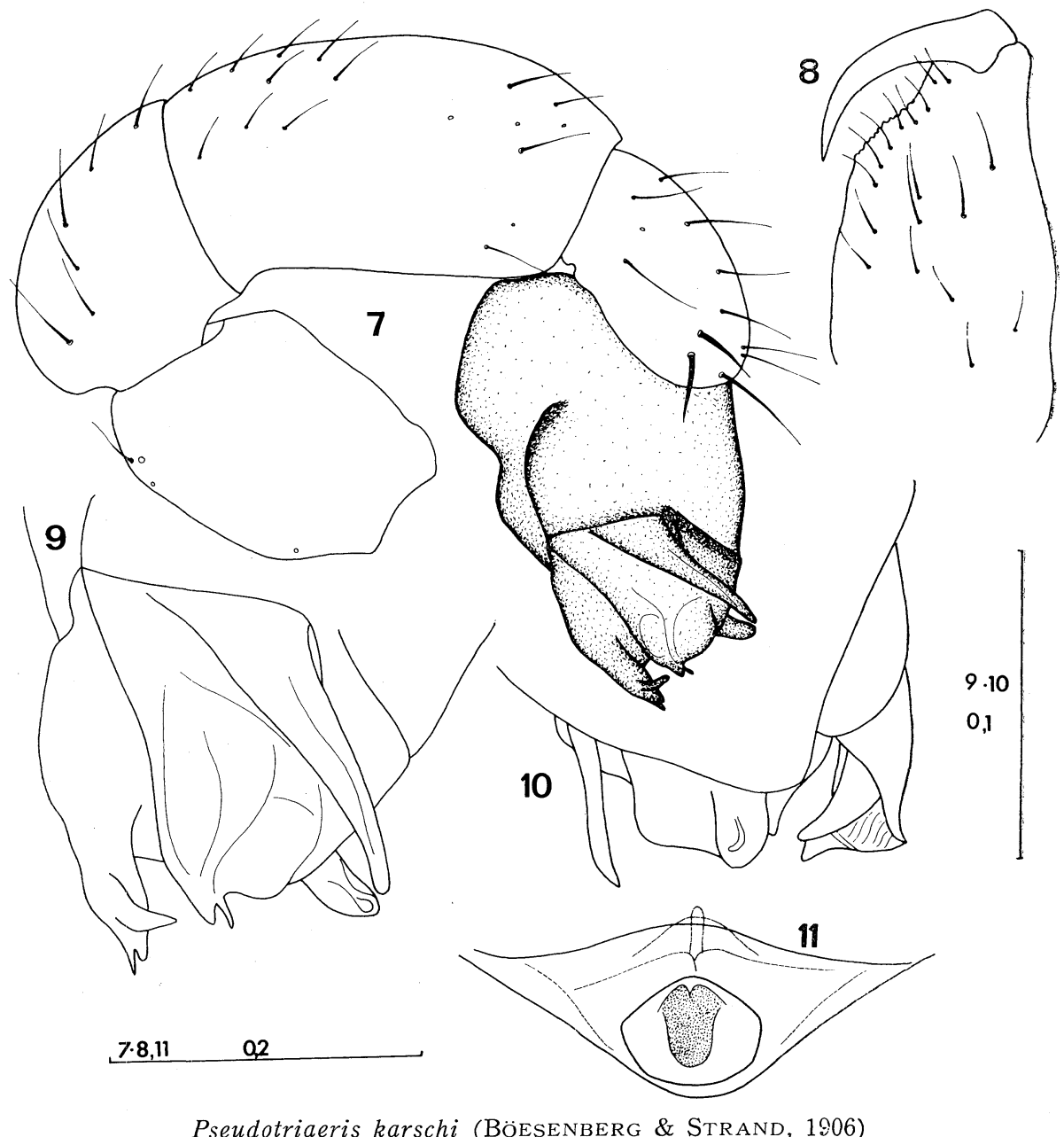

Fig. 7: pedipalp of the from the outside; fig. 8: chelicera; fig. $9,10:$ terminal part of the bulbus from the outside and the inside; fig. 11: "epigyne" and vulva; scales in $\mathrm{mm}$. 
before the epigastric furrow is somewhat sclerified; non sclerified parts white; seen from the side, the opisthosoma is somewhat quadrangular and elevated (like f. i. some Cyclosa or Episinus). Spinnerets apparently normal (not examined in detail).

우: corresponding to the $\hat{\delta}$, but sclerified ventral region more easily visible. Vulva, s. fig. 11.

Dimensions ( $\hat{\delta}$ lectotype; in $\mathrm{mm}$, slightly approximated): prosoma 0.72 long, 0.60 wide ; opisthosoma 0.96 long. Total length: 1.68 .

\begin{tabular}{ccccccc}
\hline Legs & Femora & Patellae & Tibiae & Metatarsi & Tarsi & Total \\
\hline I & 0.52 & 0.26 & 0.40 & 0.40 & 0.22 & 1.80 \\
II & 0.50 & 0.26 & 0.38 & 0.35 & 0.22 & 1.71 \\
III & 0.48 & 0.16 & 0.31 & 0.30 & 0.22 & 1.47 \\
IV & 0.62 & 0.32 & 0.50 & 0.47 & 0.26 & 2.17 \\
\hline
\end{tabular}

우: prosoma 0.76 long, 0.58 wide; opisthosoma 0.90 long. Total length : 1.66 .

\begin{tabular}{ccccccc}
\hline Legs & Femora & Patellae & Tibiae & Metatarsi & Tarsi & Total \\
\hline I & 0.56 & 0.30 & 0.43 & 0.43 & 0.22 & 1.94 \\
II & 0.53 & 0.30 & 0.41 & 0.40 & 0.22 & 1.86 \\
III & 0.45 & 0.26 & 0.33 & 0.31 & 0.22 & 1.56 \\
IV & 0.68 & 0.37 & 0.50 & 0.46 & 0.25 & 2.26 \\
\hline
\end{tabular}

Discussion: this species is practically noteworthy only for its very curious o genitalia, of an extraordinary complexity between the Oonopidae. By general morphology this species (and genus) seems near to Ischnothyreus but possibly only by convergence. The $ᄋ$ genitalia are apparently much simpler, but possibly the only individual which I could examine was not in optimal conditions (externally all seemed normal).

The affinities of this genus are for the moment completely obscure; of the genera described of the Pacific area, Tasmanoonops Hickman, 1930 (see Hickman, 1932), Subantarctia Forster, 1955, Ascuta Forster, 1956, Duripelta Forster 1956, Pounamua Forster, 1956, Kapitia Forster, 1956 (see for all Forster, 1956) have extremely simple bulbi. Yumates CHAMBERLin, 1924 (from California) can somewhat remember Pseudotriaeris by the morphology of the prosoma, but has a quite different bulbus, not so complicated (but still more than many Oonopidae). I could not find any affinity with the genera of the 
other geographical regions (it is to be noted that the $\hat{\delta}$ of some Oriental genera are unknown).

\section{Ischnothyreus formosus n. sp.}

Examined material:

Formosa, Akau, 23.4.08, H. Sauter leg., 2 方 (holo- and paratypus), 1 우 (paratypus), 10 (all Zool. Mus. Hamburg).

Description-1 : prosoma yellowish brown, somewhat elevated, but less than in $I$. narutomii; 6 prominent, adegual, eyes, in 2 straight rows, all eyes neared. Gnathocoxae with a small terminal protuberance (s. fig. 15); labium broader than long; sternum whitish, smooth, heartshaped; truncated (separates the 4 th coxae approximately of their diameter). Chelicerae, s. fig. 17; pedipalp, s. fig. 12, 18, blackish, typical of the genus. Legs whitish, femur 1 with 2 prolateral spines, tibia 1 with $3-4$ ventral spines, metatarsus 1 with $2-2$ ventral spines. Opisthosoma whitish, dorsally $3 / 4$ of it covered by a small, elongated, brown yellowish shield; ventrally no shield.

우: prosoma low, not elevated; chelicerae and gnathocoxae not modified; dorsal shield of the opisthosoma somewhat shorter (covering $2 / 3$ of it). Vulva, s. fig. 16 .

Dimensions (in mm, somewhat approximated; $\hat{\delta}$ holotypus) : prosoma 0.75 long, 0.58 wide; opisthosoma 0.75 long. Total length: 1.50 .

\begin{tabular}{ccccccc}
\hline Legs & Femora & Patellae & Tibiae & Metatarsi & Tarsi & Total \\
\hline I & 0.53 & 0.22 & 0.40 & 0.40 & 0.22 & 1.77 \\
II & 0.51 & 0.22 & 0.40 & 0.37 & 0.22 & 1.72 \\
III & 0.47 & 0.20 & 0.32 & 0.37 & 0.22 & 1.58 \\
IV & 0.65 & 0.27 & 0.47 & 0.53 & 0.28 & 2.20 \\
\hline
\end{tabular}

우 : prosoma 0.77 long, 0.60 wide ; opisthosoma 1.02 long. Total length : 1.79 .

\begin{tabular}{ccccccc}
\hline Legs & Femora & Patellae & Tibiae & Metatarsi & Tarsi & Total \\
\hline I & 0.58 & 0.22 & 0.52 & 0.43 & 0.22 & 1.97 \\
II & 0.56 & 0.22 & 0.48 & 0.43 & 0.22 & 1.91 \\
III & 0.52 & 0.20 & 0.33 & 0.42 & 0.22 & 1.69 \\
IV & 0.68 & 0.27 & 0.57 & 0.63 & 0.28 & 2.40 \\
\hline
\end{tabular}


Derivatio nominis: the Latin adjective "formosus" means beautiful (as "Formosa", the Portuguese name of the island of Taiwan).

Discussion: this species is very near to I. narutomii (NAKATSUDI) and can be distinguished from it by the genitalia.

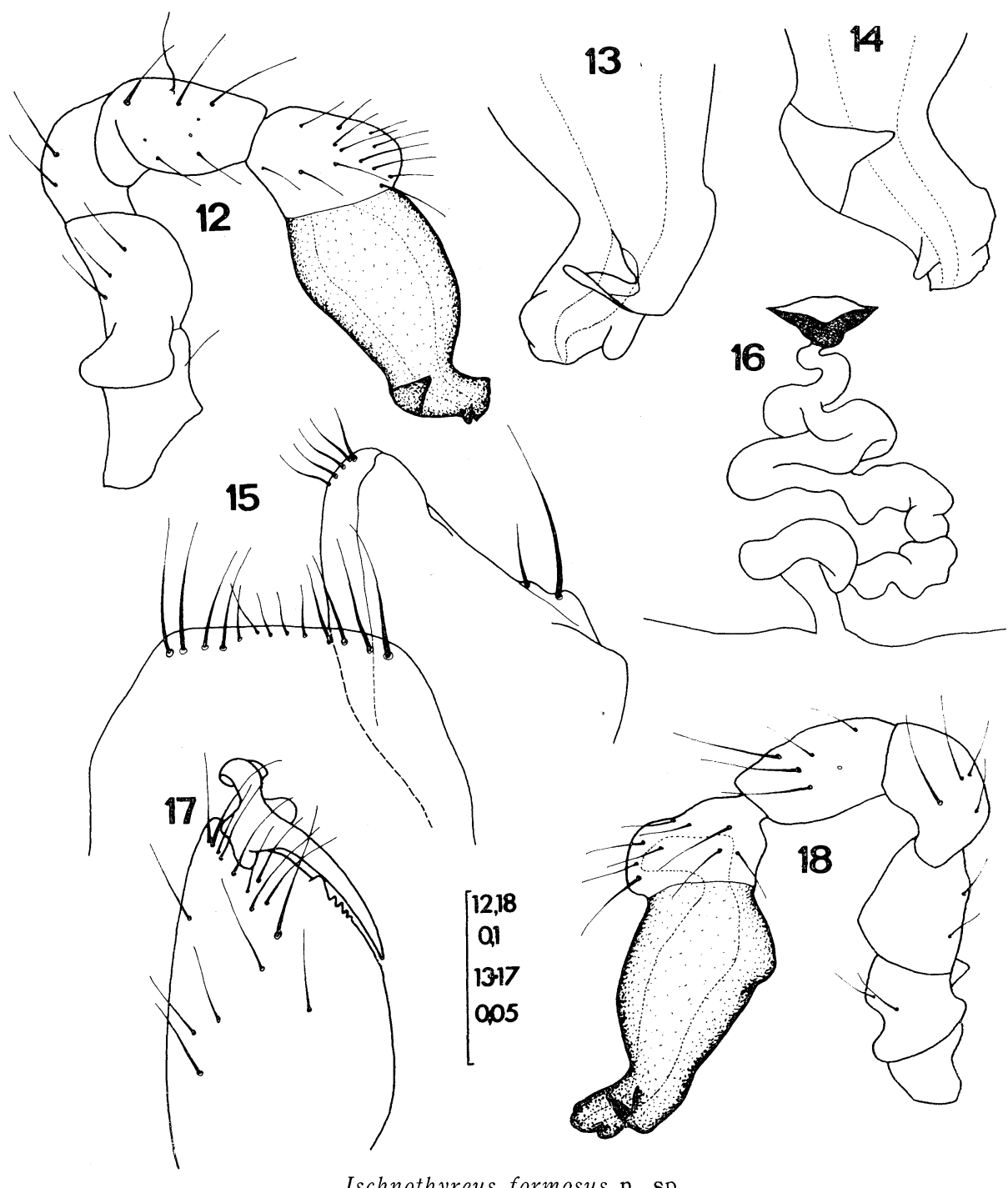

Ischnothyreus formosus $\mathrm{n} . \mathrm{sp}$.

Fig. 12, 18: pedipalp of the from the inside and the outside; fig. 13, 14 : terminal part of the bulbus from the outside and inside; fig. 15 : gnathocoxa and labium; fig. 16: vulva; fig. 17: chelicera of the $\hat{o}$; scale in $\mathrm{mm}$. 
After the redescription by CHICKERING (1968) of the generotype of Ischnothyreus Simon, 1892, I. peltifer (Simon, 1891), from the Antilles, it would seem quite probable that most of the Oonopidae with few sclerifications, blackish palpi, elongated bulbi and modifications in chelicerae and gnathocoxae of the o could be attributed to this genus. It is to be noted that SIMON (and possibly other authors) confused many (perhaps not congenerical) species under the name "I. peltifer"; as CHICKERING also observes, the illustration given by Simon (1893: 290, fig. 264) of this species does not correspond to the species of the Antilles. In the Pacific area belongs to this genus surely $I$. omus Suman, 1965 from Hawaii, whereas not at all sure is the position of $I$. lanutoo MARPLES, 1955 from Samoa ( 9 only known) and of I. pacificus RoEwER, 1963 from Micronesia.

\section{Opopaea sauteri n. sp.}

Examined material:

Formosa, Takao, 23.4.08, H. Sauter leg., 1 o (holotypus; Zool. Mus. Hamburg).

Description- $-\hat{o}$ (ㅇ unknown): prosoma not elevated, posteriorly declining somewhat abruptly, reddish brown; 6 eyes, 4 posterior in a straight row; PM somewhat larger than the others (6:5); clypeus vertical, very short. Chelicerae, s. fig. 20 ; pedipalp, s. fig. 19: as always in this genus with very enlarged patella and bulbus fused with the tarsus. Labium triangular, as broad as long; sternum dark yellowish, heartshaped, ending with a small point which separates the 4th coxae of their diameter. Legs spineless, yellowish, hairy; all articles somewhat short and thick. Opisthosoma elongated, completely covered by dorsal and ventral shields, these are yellowish brown, hairy, finely granulated.

Dimensions (in $\mathrm{mm}$, somewhat approximated; $\$$ holotype) : prosoma 0.48 long, 0.40 wide ; opisthosoma 0.66 long. Total length : 1.14 .

\begin{tabular}{ccccccc}
\hline Legs & Femora & Patellae & Tibiae & Metatarsi & Tarsi & Total \\
\hline I & 0.31 & 0.15 & 0.18 & 0.15 & 0.10 & 0.82 \\
II & 0.27 & 0.15 & 0.16 & 0.15 & 0.09 & 0.82 \\
III & 0.21 & 0.12 & 0.15 & 0.11 & 0.08 & 0.67 \\
IV & 0.31 & \multicolumn{7}{c}{ all lacking } \\
\hline
\end{tabular}



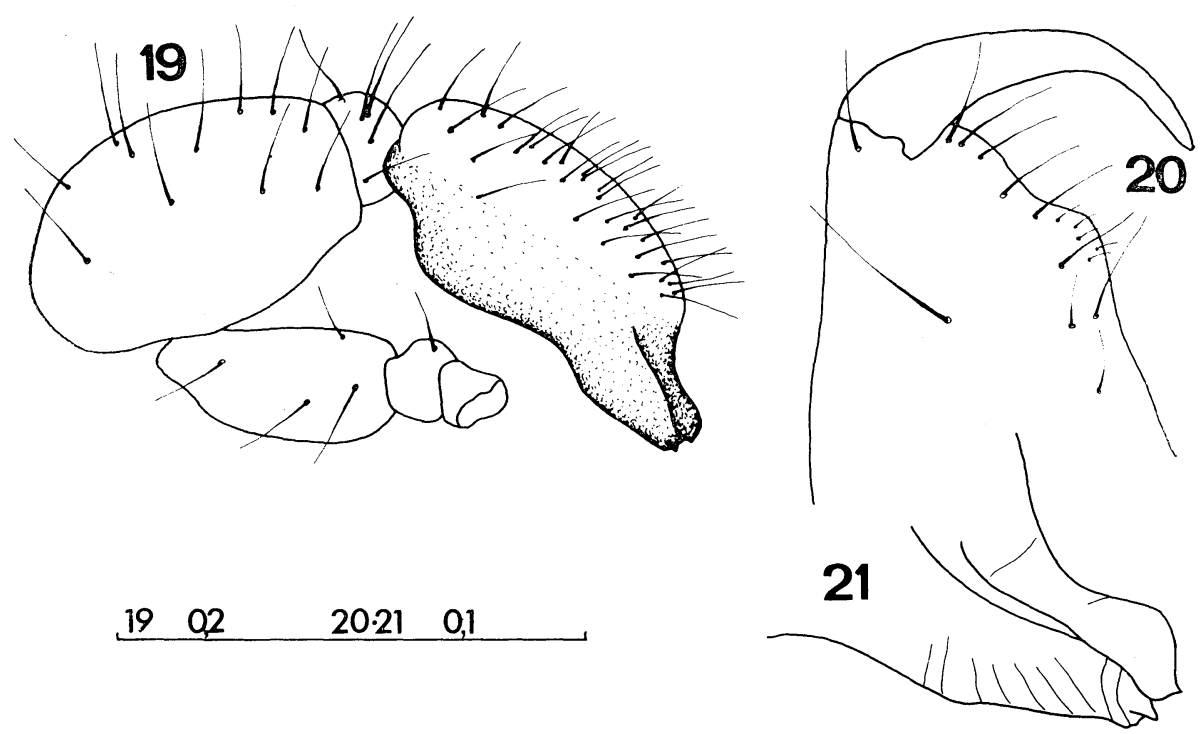

Opopaea sauteri $\mathrm{n} . \mathrm{sp}$.

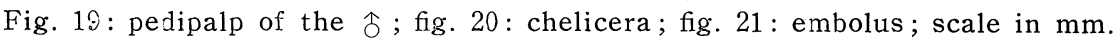

Derivatio nominis: this species is dedicated to its collector, H. SAUTER.

Discussion: notwithstanding that SIMON (1892, 1893) had illustrated and discussed the peculiar morphology of the $\$$ palp of the generotype of Opopaea (O. deserticola Simon, 1892 of St. Vincent, West Indies), the diagnosis of this genus seems to have left in doubt many authors. In O. deserticola (and in many other Oonopidae) the patella of the pedipalp is extremely enlarged, whereas the tibia is very small and globular. I incline to consider this character apomorphic (sensu HENNIG) and therefore to attribute to Opopaea all species with a similar pedipalp. Only future research shall enable to decide on the opportunity of splitting or not this genus.

To Opopaea belong many species described as Gamasomorpha: one Japanese f. i. ("Gamasomorpha" syarakuii KomATSU) which is also the nearest to O. sauteri n. sp.

Opopaea syarakui (KomATsu, 1967), comb. nov. can be easily distinguished by the morphology of the pedipalp from O. sauteri n. sp.; to the same group belongs also O. lena SumAn, 1965 from Hawaii. On the contrary, O. foveolata RoEwER, 1963 from Micronesia seems to belong to another phyletic line and remembers f.i. the species illustrated by Simon (1893) under "Ischnothyreus peltifer." 
KOMATSU (1967) has considered the most enlarged article of the palp of O. syarakui as the tibia; through this interpretation, he has been obliged to consider the last article as the bulbus (which is impossible, as in no spider the bulbus bears hairs); in his fig. 5 it can be clearly seen that also the coxa of the pedipalp had been amputated, this coxa corresponds to what KomATSU called trochanter; in very sclerified spiders it is quite easy to detach the coxa from its expansion (the lamina maxillaris).

\section{Summary}

Gamasamorpha cataphracta KARSCH, 1881 is redescribed on the types; synonym of it is Oonops corticalis BöSENBERG \& STRAND, 1906 (types examined; new synonymy). Pseudotriaeris n. gen. is described; type: Gamasomorpha karschi BösEnBERG \& STRAND, 1906), of uncertain affinities this genus is peculiar by the extreme complexity of the $\hat{\delta}$-palp. Pseudotriaeris karschi (BöSENBERG \& STRAND, 1906) comb. nov. is redescribed on the types. From Formosa are recorded or described: Gamasomorpha cataphracta KARSCH; Ischnothyreus formosus n. sp. (令 ; type. loc.: Akau), near to I. narutomii (NAKATSUDI, 1942), distinguishable from this and the other species by the genitalia; Opopaea sauteri n. sp. ( $\hat{\delta}$, 우 unknown; typ. loc.: Takao), near to O. syarakui (KomATsu, 1967) comb. nov. (described as Gamasomorpha), distinguishable by the genitalia. Some considerations are made over taxonomical problems in the genera Gamasomorpha and Opopaea.

\section{References}

Berland, L., 1933. Araignées des îles Marquises. Bernice P. Bishop Mus. Bull., 114 : 39-70.

Boesenberg, W. \& E. Strand, 1906. Japanische Spinnen. Abh. Senck. Naturf. Ges., $30: 93-422$.

Brignoli, P. M., 1972. Some cavernicolous spiders from Mexico. Quard. Acc. Naz., Lincei, $171:$ : 129-155.

Chamberlin, R. V., 1924. The spider fauna of the shores and islands of the gulf of California. Proc. Calif. Acad. Sci., 12: 561-694.

Chickering, A. M., 1968. The zenus Ischnothyreus in Central America and the West Indies. Psyche, $75: 77-86$.

Forster, R. R., 1956. New Zealand spiders of the family Oonopidae. Rec. Canterbury Mus., $7: 89-169$.

Hickman, V. V., 1932. Studies in Tasmanian spiders. Part V. Pap. Proc. Roy. Soc. Tasm., 1931: 20-31. 
KARsch, F., 1881. Diagnoses Arachnodarum Japoniae. Berl. Ent. Ztschr., 25 : 35-40. Kayashima, I., 1943. Spiders of Formosa. Tooto Book Company, Tokyo. 1-94.

Komatsu, T., 1963. Three new cave spiders of genera Gamasomorpha and Masirana. Acta Arachnol., 18 : 21-26.

Komatsu, T., 1967. Two new Japanese spiders (Gamasomorpha, Oonopidae and Leptoneta, Leptonetidae). Acta Arachnol., $20: 46-49$.

Komatsu, T., 1968. Two new spiders of genera Tetrablemma and Dolichocybaeus. Acta Arachnol., $21: 35-39$.

Marples, B. J., 1955. Spiders from Western Samoa. Journ. Linn. Soc. London, 42: 453-504.

Nakatsudi, K., 1942. Arachnida from Izushichito. Journ. Agr. Sci. Tokyo Nogyo Daigaku, 1(4) : 287-328.

Or, R., 1955. A new species of genus Orchestina from Japan. Acta Arachnol.," 14 : $41-44$.

OI, R., 1958. Three new species of the six-eyed spiders. Acta Arachnol., 15: 31-36.

OKADA, Y., 1959. An annotated list of animals of Okinawa islands. Naha. 1-384 (spiders by KISHIDA, H., pp. 367-384).

Roewer, C.F., 1963 Araneina: Orthognatha, Labidognatha. Insects of Micronesia, $3(4): 105-132$.

Simon, E., 1891. On the spiders of the island of St. Vincent. Part 1. Proc. Zool. Soc. London, 1891 : 549-575.

Simon, E., 1893. Histoire naturelle des araignées. Paris. 1:257-488.

Suman, T.W., 1965. Spiders of the family Oonopidae in Hawaii. Pacif. Insects, 7 : $225-242$. 